\title{
Evaluation of Ischemic and Hemorrhagic Stroke on Computed Tomography
}

\author{
Shahzaib Rehmani* \\ Student, Superior College Lahore, University Campus, 17-KM Raiwaind Road, Kot Arain, Lahore, Pakistan \\ Madina Rasheed \\ Student, Superior College Lahore, University Campus, 17-KM Raiwaind Road, Kot Arain, Lahore, Pakistan \\ Ghasiqa Rafique \\ Student, Superior College Lahore, University Campus, 17-KM Raiwaind Road, Kot Arain, Lahore, Pakistan \\ Sybil Rose \\ Lecturer, Superior College Lahore, University Campus, 17-KM Raiwaind Road, Kot Arain, Lahore, Pakistan
}

Saboohi Saeed

Head of Department of Physiology Department, Azra Naheed Medical College, Lahore, 17-KM Raiwaind Road, Kot Arain, Lahore, Pakistan

Rana Muhammad Athar Azeem Shams

Lecturer, Superior College Lahore, University Campus, 17-KM Raiwaind Road, Kot Arain, Lahore, Pakistan

Rana Muhammad Bakhtwar Khan Sajawal

Lecturer, Superior College Lahore, University Campus, 17-KM Raiwaind Road, Kot Arain, Lahore, Pakistan

Ambreen Sadaf

Lecturer, The University of Lahore, 1-KM Defence Road, near Bhuptian Chowk, Lahore, Pakistan

The research is financed by Asian Development Bank. No. 2006-A171(Sponsoring information)

\section{Abstract}

The stroke is the 3rd leading cause of death in Pakistan, wherein back in 2009, stroke used to be the $4^{\text {th }}$ leading cause of death in Pakistan, a 19.2\% increase is alarming (IHME, 2019). Ischemic stroke occurs 75-80 percent of the time, while hemorrhagic stroke occurs 8-20 percent of the time. The objective of our study is to evaluate the frequency and ratio of ischemic and hemorrhagic stroke on computed tomography. A Descriptive study was performed using non-probability convenient sampling technique. The study was conducted in Lahore General Hospital, Lahore, Pakistan. The data was collected from November 15, 2020 to February 15, 2021. Informed consent was taken from all the participants. In our study patients with provisional diagnose of clot or thrombosis, History of Ischemic Stroke, History of Hemorrhagic Stroke, patients who came with clinical manifestation of stroke, traumatic or Road Traffic Accidents (RTA) patients, patients with cerebral Transient Ischemic Stroke. Arterial Puncture in Last 7 days, patients with Active bleeding, peroneal nerve injuryand patients who have been injected Botulinum Toxic Injection in last 3 months were included in our study. Patients who had a previous history of Parkinson disease, patients not having any apparent cause or chronic or acute symptoms of stroke, no history of internal bleeding, patients with chronic cerebral disease and patients with other neurological defects were excluded.A total of 85 patients with Stroke were included in our study. Most of the patients were 40 to 65 years of age. The average age of the patients was $59.5 \pm 11.1$ years. Out of 85 there were $38.8 \%(\mathrm{P}=33)$ positive with $\mathrm{H} / \mathrm{O}$ Infarction females $(\mathrm{P}=11)$ and males $(\mathrm{P}=22) 55(62.5 \%)$ were males and $33(37.5 \%)$ were females with 1.62 : 1 male to female ratio as shown in Fig 5.2. Ischemic stroke was observed in 33 (36.2\%) patients and 40 (47.3\%) were suffered hemorrhagic stroke and $12(14.4 \%)$ patients were affected with TIA.The conclusion to this study is that to assess early stroke with extreme clarity, computed tomography is the safest modality for evaluating stroke patients and allows radiologists to more accurately assess these patients on CT in terms of prognosis, frequency, morbidity, and legitimacy.

Keywords: Stroke, Hemorrhagic Stroke, Ischemic Stroke, Cerebral Infarction, Computed Tomography

DOI: $10.7176 / \mathrm{JHMN} / 90-06$

Publication date:June $30^{\text {th }} 2021$

\section{Introduction}

The cell death to brain tissue after the onset of Stroke is characterized as a sudden onset of clinical symptoms of a focal (or global) impairment of cerebral activity that lasts longer than 24 hours or results in death, with no obvious 
cause other than a vascular cause ${ }^{[1]}$.

The stroke is the 3rd leading cause of death in Pakistan, wherein back in 2009 , stroke used to be the $4^{\text {th }}$ leading cause of death in Pakistan, a 19.2\% increase is alarming (IHME, 2019) [2]. Ischemic stroke occurs 75-80 percent of the time, while hemorrhagic stroke occurs 8-20 percent of the time ${ }^{[3]}$.

In an embolic stroke, blood clots or debris from somewhere in the body, usually the heart valves, enter the circulatory system and block smaller blood arteries. cells normally do not survive and ultimately die ${ }^{[4]}$. While the ischemic penumbra has been clinically silent, it is still metabolically active. Age, sex, and family history are both risk factors for ischemic stroke. A transient ischemic attack, on the other hand, is a vascular disturbance that lasts less than 24 hours and has little signs of infarction on CT imaging ${ }^{[5]}$. The main pathologies include hypertension, atherosclerosis leading to coronary artery disease, dyslipidemia, cardiac and Patients may have fatigue on one side of their body, vision issues, muscle paralysis depending on the infected artery, dizziness, confusion, loss of balance, pain in the neck region, hand tremors, and fluctuations in the pulse rate gate disturbance ${ }^{[6]}$.

Ischemic stroke occurs as blood supply to the brain is decreased, leading to the death of neurons. A hemorrhagic stroke occurs when a blood clot in the brain bursts, causing internal bleeding in the brain 2 . Subarachnoid hemorrhage (SAH) and intra-cerebral hemorrhage (ICH) are the two forms of hemorrhagic stroke (ICH). Diabetes, elevated blood pressure $(115 / 75 \mathrm{mmHg})$, obesity, alcohol, and physical inactivity are among these causes ${ }^{[7]}$. According to a report conducted in the United States, 62 percent of women died as a direct result of a stroke. Non-contrast computerized tomography can detect acute ischemic stroke and intra-cerebral stroke (NCCT). It is thought to be an excellent therapy for diagnosing $\mathrm{ICH}$, as well as being accessible and cost-effective. ${ }^{[8]}$

Ischemic stroke and were reported within one month of the stroke's occurrence were reviewed, Using computed tomography (CT) ${ }^{[9]}$. Spontaneous HT was observed in 50 patients $(12.3 \%)$, with 33 cases of hemorrhagic infarction (66\%), 17 cases of parenchymal hematoma (34\%), 32 cases of non-symptomatic HT (64\%), and 18 cases of symptomatic HT (36 percent). CT or MRI is used to identify the condition in $40 \%$ of HT cases within 4-7 days of the onset of symptoms. Using multivariate logistic regression, atrial fibrillation (OR 4.88, 95 percent CI $1.83-13.00, \mathrm{P}=0.002)$ and infarct region $(\mathrm{OR} 4.48,95$ percent CI $1.85-10.85, \mathrm{P}=0.001)$ were described as independent markers of HT in ischemic stroke. Random HT was not associated with a worse 3-month prognosis for ischemic stroke, according to multivariate regression (OR 1.59, 95 percent CI 0.38-6.69, $\mathrm{P}=0.527$ ) ${ }^{[10]}$. In 12.3 percent of our ischemic stroke patients, atrial fibrillation and a major infarct area were independent predictors of spontaneous HT. ${ }^{[11][12]}$ A CT scan is the screening tool of use in patients with acute stroke since it can detect ICH within minutes of the onset of the stroke. first It is non-invasive and secure, and it can be used to assess the size of the hematoma, the cause of the hemorrhage, the involvement of intra-ventricular, subarachnoid, or subdural fluid, and whether there is a mass effect in primary non-traumatic ICH. ${ }^{[13][14]}$ As a result, estimating functional outcome from a single CT scan of the brain conducted during patient induction is a vital task for the surgeon ${ }^{[15]}$. To assess the proficiency of computed tomography (CT-scan) in predicting irreversible ischemic brain damage, and its relationship with the onset of stroke within six hours of damage, for this purpose, researchers took up the CT-scans of 786 patients, CT-scans within 6 hours of onset of stroke, after a day and after seven days, as well as follow-up CT-scans were obtained and compared. The results showed a positive predictive value of $85 \%$, whereas sensitivity and negative predictive values were $64 \%$, it can be concluded that after an ischemic stroke CT specifically detects irreversible ischemic brain damage within 6 hours of onset. ${ }^{[21]}$ To assess the proficiency of computed tomography (CT-scan) in predicting irreversible ischemic brain damage, and its relationship with the onset of stroke within six hours of damage, for this purpose, researchers took up the CT-scans of 786 patients, CTscans within 6 hours of onset of stroke, after a day and after seven days, as well as follow-up CT-scans were obtained and compared. The results showed a positive predictive value of $85 \%$, whereas sensitivity and negative predictive values were $64 \%$, it can be concluded that after an ischemic stroke CT specifically detects irreversible ischemic brain damage within 6 hours of onset. ${ }^{[21]}$

The aim of this study was to determine how we can predict short-term in-hospital mortality and morbidity using CT scan results, as well as how hematoma volume, stroke location, midline transition, intra-ventricular bleed extension, ventricle compression, and other variables influence clinical outcome in patients with acute stroke.

\subsection{Materials and Methods}

A Descriptive study was performed in Lahore General Hospital, Lahore, Pakistan. Non-Probability Convenient Sampling Technique was used. The data was collected from November 15, 2020 to February 15, 2021.The rules and regulations set by the ethical committee of The Superior College, Lahore were followed while conducting the research and the rights of the research participants were respected. Written informed consent attached was taken from all the participants. Total 85 patients were included in our study, out of which 30 were females and 55 were male. In our study patients with provisional diagnose of clot or thrombosis, History of Ischemic Stroke, History of Hemorrhagic Stroke, patients who came with clinical manifestation of stroke, traumatic or Road Traffic Accidents (RTA) patients, patients with cerebral Transient Ischemic Stroke. Arterial Puncture in Last 7 days, patients with Active bleeding, peroneal nerve injuryand patients who have been injected Botulinum Toxic Injection in last 3 
months were included in our study. Patients who had a previous history of Parkinson disease, patients not having any apparent cause or chronic or acute symptoms of stroke, no history of internal bleeding, patients with chronic cerebral disease and patients with other neurological defects were excluded.

In this study informed consent was obtained from patients. We reviewed our data-base of patients who underwent non-enhanced CT Brain. Symptoms for imaging included hypertension, atherosclerosis leading to coronary artery disease, dyslipidemia, cardiac arrest and Patients may have fatigue or numbness on one side of their body, vision issues, muscle paralysis depending on the infected artery, dizziness, confusion, loss of balance, pain in the neck region, hand tremors, and fluctuations in the pulse rate gate disturbance and those patients who came with internal \& spot bleeding in Emergency department. Non-Enhanced CT (Toshiba 64) was performed from chin to vertex axial coronal view and images reconstructed at $1 \mathrm{~mm}$ for reporting and $5 \mathrm{~mm}$ for filming. The brain was visualized in both sagittal and axial planes. Intra Cerebral Hemorrhage, IH were also diagnosed down up to the brain stem with just around the mid brain. All findings of Non-Enhanced CT were considered by the advice of consultant radiologist.

Data was tabulated and analyzed with the help of statistical package for the social sciences (SPSS) 25 and Microsoft excel (2016). Data was reported using cross sectional descriptive statistics. The result of quantitative variables like age, duration of stroke, presented in mean and standard deviation. The qualitative variables like gender were reported using percentages and frequencies. Bar chart were given.

1.1.1 Results

A total of 85 patients with Stroke were included in our study. Most of the patients were 40 to 65 years of age. The average age of the patients was $69.5 \pm 11.1$ years. Out of 85 there were $38.8 \%(\mathrm{P}=33)$ positive with $\mathrm{H} / \mathrm{O}$ Infarction females $(\mathrm{P}=11)$ and males $(\mathrm{P}=22)$ as shown in Table-5.1

Out of 85 stroke patients, $55(62.5 \%)$ were males and $33(37.5 \%)$ were females with 1.62: 1 male to female ratio as shown in Fig 5.2. Ischemic stroke was observed in $33(36.2 \%)$ patients and $40(47.3 \%)$ were suffered hemorrhagic stroke and $12(14.4 \%)$ patients were affected with TIA as shown in Table.5.2.

There were $60 \%(\mathrm{P}=51)$ patients have increased ICP out of $n=85$ as shown in Table-5.3. Frequency of stroke by the location of affected areas is presented in Table 5.4. Out of 85 patients, $22.3 \%(\mathrm{p}=19)$ patients were affected with frontal lobe, $29.41 \%(\mathrm{p}=25)$ patients were categorized most common affected site as Right Hemisphere, $16.4 \%$ $(p=14)$ patients were affected with Left Hemisphere, 21.1\% $(p=18)$ patients were affected with Parietal lobe and only10\% $(\mathrm{p}=9)$ patients were presented with Occipital Stroke as shown in Table. 5.4.

Frequency of modifiable Mass Effect and Midline Shift with regards to the Hemorrhage and Ischemic stroke is presented in Table-5.5. Hydrocephalus was $34.11 \%(\mathrm{P}=29)$ in both types of storks in ischemic stroke and hemorrhagic stroke. There were $21.17 \%(\mathrm{P}=18)$ patients were shown the midline shift in AIS and ICH. Both Midline herniation and Hydrocephalus were also observed in $16.47 \%(\mathrm{P}=14)$ and $28.29 \%(\mathrm{P}=24)$ subjects with no Mass Effect.

The most common Affected Vessel were also observed on CT as shown in Table-5.6. Rate of MCA 57.64\% $(\mathrm{P}=49)$, ACA $15.3 \%(\mathrm{P}=13)$ \& $\mathrm{PCA} 27.1 \%(\mathrm{P}=23)$ Involvement were significantly high in Male than Female $(\mathrm{p}<0.01)$ as presented in Fig.5.6.

\subsubsection{Discussion}

Out of 85 patients suffering from stroke disease, 55 patients were male, and 30 patients were female. There was age group between 20-73. Our study suggested that 33 patients had an ischemic stroke in which 12 patients were female, and 21 patients were male. Moreover, 40 patients had a hemorrhagic stroke, where 13 patients were female, and 27 were male. 12 patients having a transient ischemic attack, where 5 patients were female, and 7 patients were male. Stroke is defined as a sudden onset focal neurological deficit that is thought to be caused by a vascular malfunction. The artery blockage leads to ischemic stroke, blood vessel leakage or burst cause hemorrhagic stroke, and temporary disruption of blood flow leads to transient stroke.

Our study evaluates by using a computed tomography imaging technique. CT scans will also demonstrate the size and location of tumors, blood vessel defects, blood clots, and other brain anomalies. CT scans are the most common way to tell whether a stroke is ischemic or hemorrhagic.

Abdul Aziz Sahto et al., in their study, "comparative study to assess the frequency of ischemic and hemorrhagic stroke and associated risk factors in patients with hypertension" their study revealed the frequency of ischemic and hemorrhagic stroke and associated risk factors in patients with hypertension. According to this study, ischemic stroke was diagnosed in 105 (66\%) patients; however, hemorrhagic stroke was observed in 55 (34\%) patients. In both ischemic and hemorrhagic strokes, hypertension was present in $100 \%$ of the storks. In hemorrhagic stroke, the rates of diabetes, dyslipidemia, and smoking were significantly higher than in ischemic stroke (p0.01). They found a high ischemic stroke prevalence in our population compared to hemorrhagic stroke. Both ischemic and hemorrhagic stroke patients had high levels of hypertension, dyslipidemia, diabetes, and smoking. In this study, the factors predisposing to ischemic vs. hollow stroke were identified in patients with high 
blood pressure. A cohort study, including hypertensive patients, was performed at Aga Khan University Hospital (AKUH) in Karachi. More than 500 CVA patients have been diagnosed with ischemic or hemorrhagic patients for approximately two years in their observation.

The author found that over $65 \%$ of patients had underlying hypertension, with about half of them hospitalized for the first time because of the CVA. Similarly, our study findings support significantly stronger hemorrhagic stroke in patients with HTN, DM, Dyslipidemia, and smoking in ischemic stroke. Furthermore, this difference in dyslipidemia and smoking between hemorrhagic and ischemic strokes was significant. They have found a high ischemic stroke prevalence in our population as hemorrhagic stroke. In ischemic and hemorrhagic stroke patients, gender, hypertension, dyslipidemia, diabetes, and smoking were associated factors.

\subsubsection{Conclusion}

The conclusion to this study is that to assess early stroke with extreme clarity, computed tomography is the safest modality for evaluating stroke patients and allows radiologists to more accurately assess these patients on CT in terms of prognosis, frequency, morbidity, and legitimacy.

\section{References}

1. Grysiewicz RA, Thomas K, Pandey DK. Epidemiology of ischemic and hemorrhagic stroke: incidence, prevalence, mortality, and risk factors. Neurologic clinics. 2008 Nov 1;26(4):871-95.

2. Katan M, Luft A. Global burden of stroke. InSeminars in neurology 2018 Apr (Vol. 38, No. 2, pp. 208-211). Georg Thieme Verlag.

3. Shiber JR, Fontane E, Adewale A. Stroke registry: hemorrhagic vs ischemic strokes. The American journal of emergency medicine. 2010 Mar 1;28(3):331-3.

4. Radu RA, Terecoasă EO, Băjenaru OA, Tiu C. Etiologic classification of ischemic stroke: Where do we stand? Clinical neurology and neurosurgery. 2017 Aug 1;159:93-106.

5. Yamada Y, Metoki N, Yoshida H, Satoh K, Ichihara S, Kato K, Kameyama T, Yokoi K, Matsuo H, Segawa $\mathrm{T}$, Watanabe S. Genetic risk for ischemic and hemorrhagic stroke. Arteriosclerosis, thrombosis, and vascular biology. 2006 Aug 1;26(8):1920-5.

6. Feigin VL, Krishnamurthi RV, Parmar P, Norrving B, Mensah GA, Bennett DA, Barker-Collo S, Moran AE, Sacco RL, Truelsen T, Davis S. Update on the global burden of ischemic and hemorrhagic stroke in 19902013: the GBD 2013 study. Neuroepidemiology. 2015;45(3):161-76.

7. Zhang Y, Tuomilehto J, Jousilahti P, Wang Y, Antikainen R, Hu G. Lifestyle factors and antihypertensive treatment on the risks of ischemic and hemorrhagic stroke. Hypertension. 2012 Oct;60(4):906-12.

8. Davis DP, Robertson T, Imbesi SG. Diffusion-weighted magnetic resonance imaging versus computed tomography in the diagnosis of acute ischemic stroke. The Journal of emergency medicine. 2006 Oct 1;31(3):269-77.

9. Murphy BD, Fox AJ, Lee DH, Sahlas DJ, Black SE, Hogan MJ, Coutts SB, Demchuk AM, Goyal M, Aviv RI, Symons S. Identification of penumbra and infarct in acute ischemic stroke using computed tomography perfusion-derived blood flow and blood volume measurements. Stroke. 2006 Jul 1;37(7):1771-7.

10. von Kummer R. The impact of computed tomography on acute stroke treatment. InThrombolytic Therapy for Acute Stroke 2005 (pp. 249-278). Humana Press.

11. Lövblad KO, Baird AE. Computed tomography in acute ischemic stroke. Neuroradiology. 2010 Mar 1;52(3):175-87.

12. Chhetri PK, Raut S. Computed tomography scan in the evaluation of patients with stroke. Journal of College of Medical Sciences-Nepal. 2012 Sep 12;8(2):24-31.

13. Hatano S. Experience from a multicentre stroke register: a preliminary report. Bulletin of the World Health Organization. 1976;54(5):541.

14. Ruíz DS, Murphy K, Gailloud P. 320-Multidetector row whole-head dynamic subtracted CT angiography and whole-brain CT perfusion before and after carotid artery stenting. European journal of radiology. 2010 Jun $1 ; 74(3): 413-9$

15. Jadhav AP, Desai SM, Kenmuir CL, Rocha M, Starr MT, Molyneaux BJ, Gross BA, Jankowitz BT, Jovin TG. Eligibility for endovascular trial enrollment in the 6-to 24-hour time window: analysis of a single comprehensive stroke center. Stroke. 2018 Apr;49(4):1015-7.

16. Reidler P, Stueckelschweiger L, Puhr-Westerheide D, Feil K, Kellert L, Dimitriadis K, Tiedt S, Herzberg M, Rémi J, Liebig T, Fabritius MP. Performance of Automated Attenuation Measurements at Identifying Large Vessel Occlusion Stroke on CT Angiography. Clinical neuroradiology. 2020 Sep 16:1-0.

17. Byrne D, Walsh JP, Schmiedeskamp H, Settecase F, Heran MK, Niu B, Salmeen AK, Rohr B, Field TS, Murray N, Rohr A. Prediction of hemorrhage after successful recanalization in patients with acute ischemic stroke: improved risk stratification using dual-energy CT parenchymal iodine concentration ratio relative to the superior sagittal sinus. American Journal of Neuroradiology. 2020 Jan 1;41(1):64-70. 
18. Zaharchuk G, El Mogy IS, Fischbein NJ, Albers GW. Comparison of arterial spin labeling and bolus perfusion-weighted imaging for detecting mismatch in acute stroke. Stroke. 2012;43(7):1843-8.

19. Chhetri P, Raut S. Computed tomography scan in the evaluation of patients with stroke. Journal of College of Medical Sciences-Nepal. 2012;8(2):24-31.

20. Gautam A, Raman B. Segmentation of ischemic stroke lesion from $3 \mathrm{~d} \mathrm{mr}$ images using random forest. Multimedia Tools and Applications. 2019;78(6):6559-79.

21. Jog A, Carass A, Roy S, Pham DL, Prince JL. Random forest regression for magnetic resonance image synthesis. Med Image Anal. 2017;35:475-88.

\section{Gender * H/O Infract:}

Table No 5.1: $\quad n=85$

\begin{tabular}{ll|c|c|c} 
& & \multicolumn{2}{c}{ H/O Infract } & TES \\
\hline Gender & NO & 19 & 11 & 30 \\
& Female & 33 & 22 & 55 \\
\hline Total & Male & 52 & 33 & 85 \\
\hline
\end{tabular}

Table 1:Gender-wise frequency of Infraction

\section{Graph5.1: Gender-wise frequency of types of stroke}

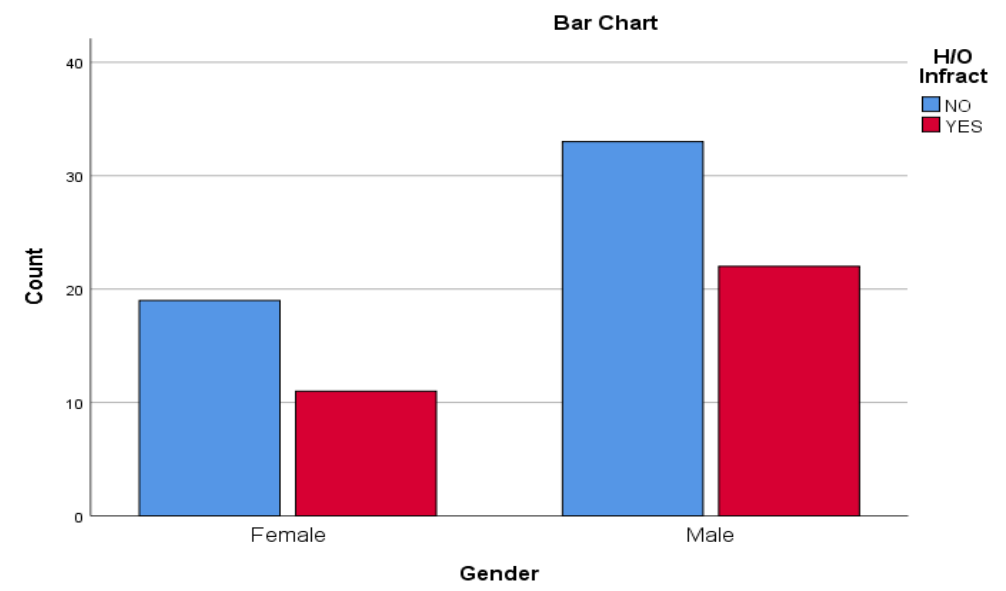

Table: $5.2: \mathrm{n}=\mathbf{8 5}$

Type of Stroke

\begin{tabular}{ll|r|r|r|r} 
& & Ischemic stroke & Hemorrhagic stroke & Transient ischemic attack & Total \\
\hline \multirow{2}{*}{ Gender } & Female & 12 & 13 & 5 & 30 \\
\cline { 2 - 7 } & Male & 21 & 27 & 7 & 55 \\
\hline \multirow{2}{*}{ Total } & 33 & 40 & 12 & 85 \\
\hline
\end{tabular}

Gender-wise frequency of types of stroke

\section{Graph:5.2}

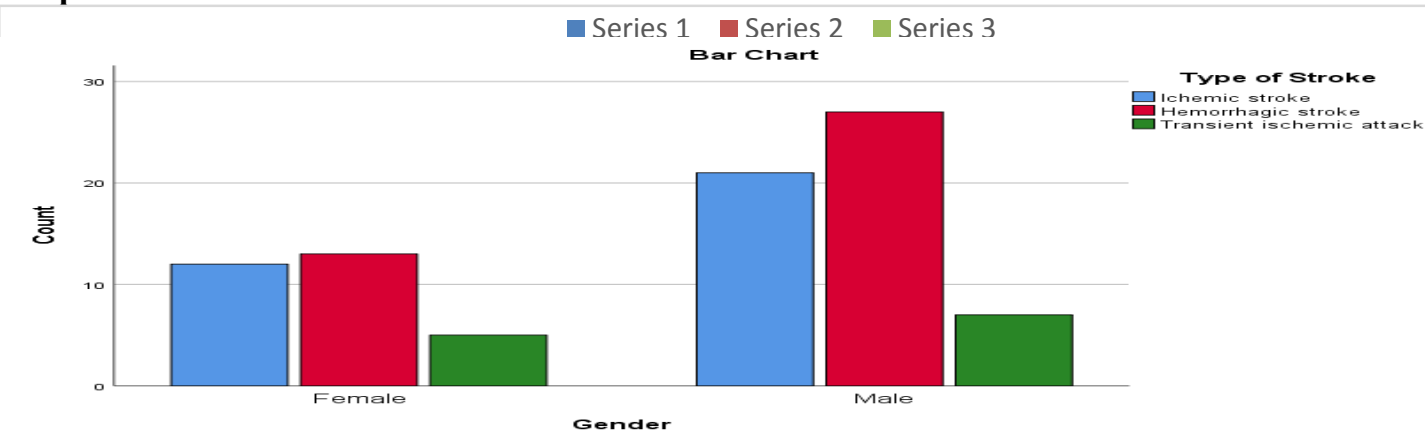

Increased ICP

Gender-wise frequency of types of stroke 
Table No. 5.3. $n=85$

\begin{tabular}{lccc|c|c} 
& & \multicolumn{2}{c}{ Increased ICP } & \multicolumn{2}{c}{ Total } \\
\hline \multirow{3}{*}{ Gender } & & NO & YES & 30 \\
\cline { 2 - 5 } & & Female & 12 & 18 & 55 \\
\hline & Male & 22 & 33 & 85 \\
\hline
\end{tabular}

Fig : 5.3

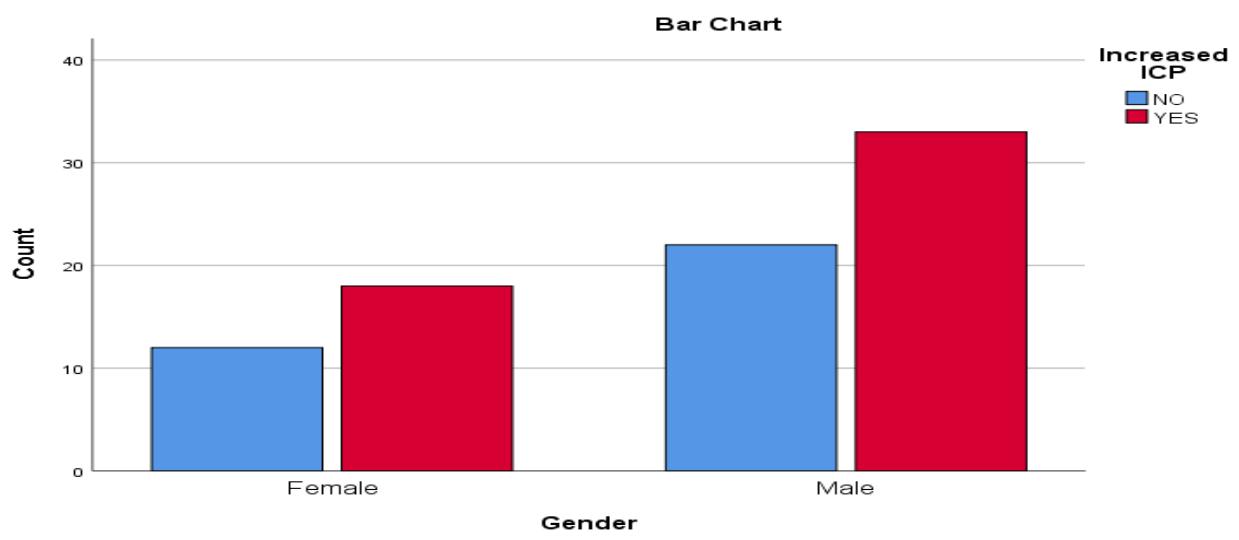

Gender-wise frequency of Increase intracranial pressure

Table No.5.4: $n=85$

\begin{tabular}{|c|c|c|c|c|c|c|c|}
\hline & & \multicolumn{5}{|c|}{ Location of affected areas } & \multirow[b]{2}{*}{ Total } \\
\hline & & Frontal Lobe & $\begin{array}{c}\text { Right } \\
\text { Hemi-sphere }\end{array}$ & $\begin{array}{c}\text { Left } \\
\text { Hemi-sphere }\end{array}$ & Parietal Lobe & $\begin{array}{l}\text { Occipital } \\
\text { Lobe }\end{array}$ & \\
\hline \multirow[t]{2}{*}{ Gender } & Female & 7 & 9 & 5 & 5 & 4 & 30 \\
\hline & Male & 12 & 16 & 9 & 13 & 5 & 55 \\
\hline Total & & 19 & 25 & 14 & 18 & 9 & 85 \\
\hline
\end{tabular}

Gender-wise frequency of location of affected areas

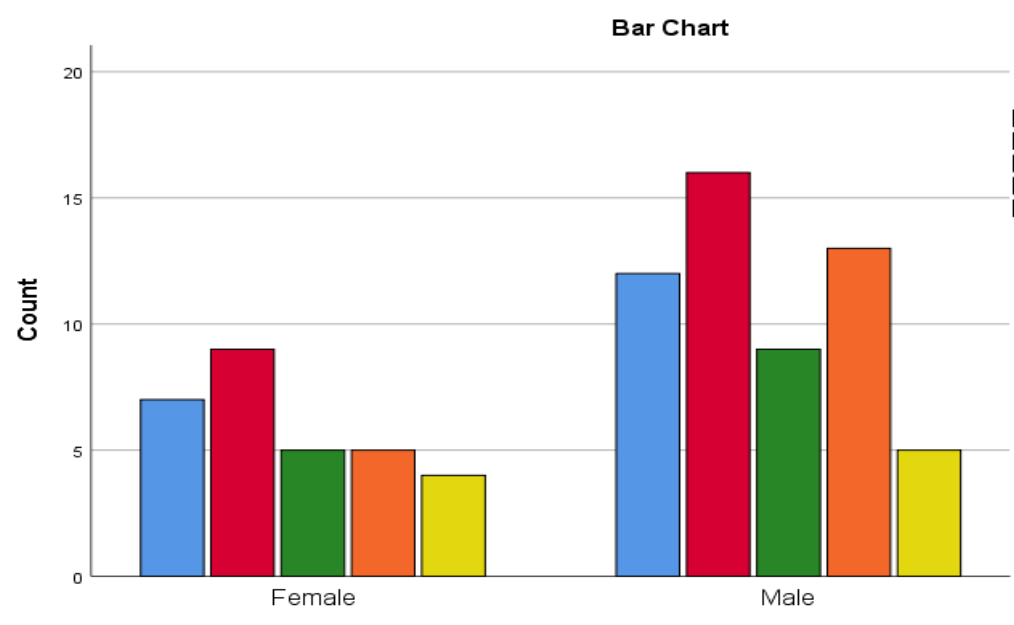

Location of affected ares

$\square$ Frontal Lobe

Right Hemishpere

Right Hemishpere

Parental Lobe

Occipital Lobe

Gender 
Fig: 5.4

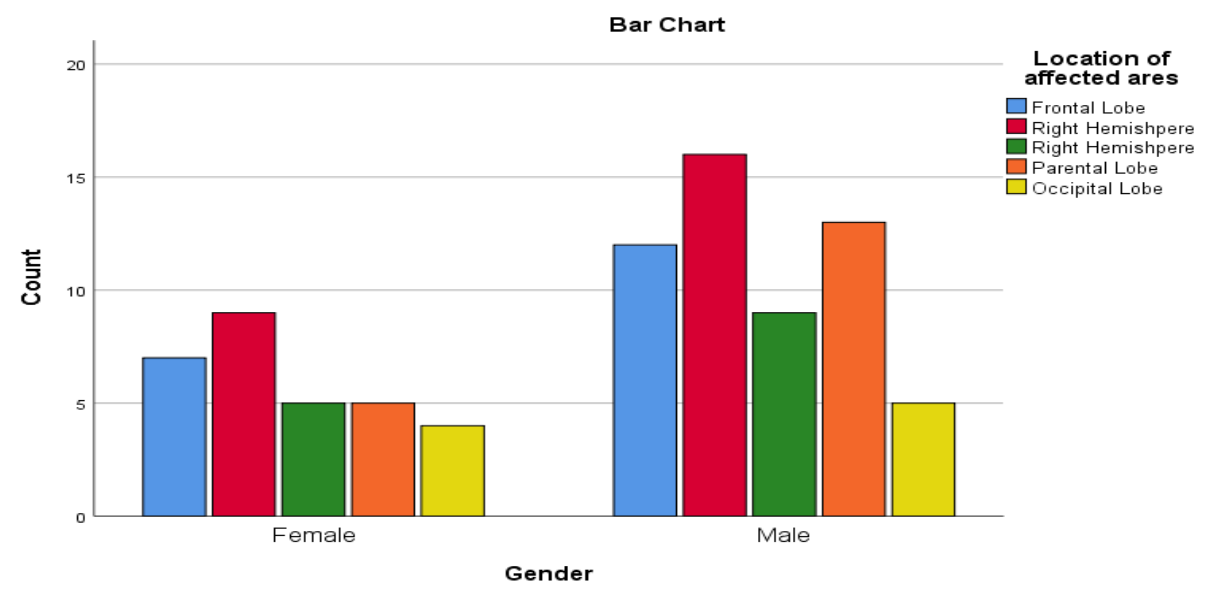

Gender-wise frequency of location of affected areas

Mass Effect

Table: 5.5: $\mathrm{n}=\mathbf{8 5}$

Mass Effect

\begin{tabular}{l|l|l|l|l} 
Midline shift & Hydrocephlus & No Mass Effect & Both Midline and Hydrocephus & Total \\
\hline
\end{tabular}

\begin{tabular}{ccc|c|c|c|c}
\hline Gender & Female & 5 & 11 & 9 & 5 & 30 \\
\cline { 2 - 7 } & Male & 13 & 18 & 15 & 9 & 55 \\
\hline Total & 18 & 29 & 24 & 14 & 85 \\
\hline
\end{tabular}

Gender-wise frequency of mass effect

Fig:5.5

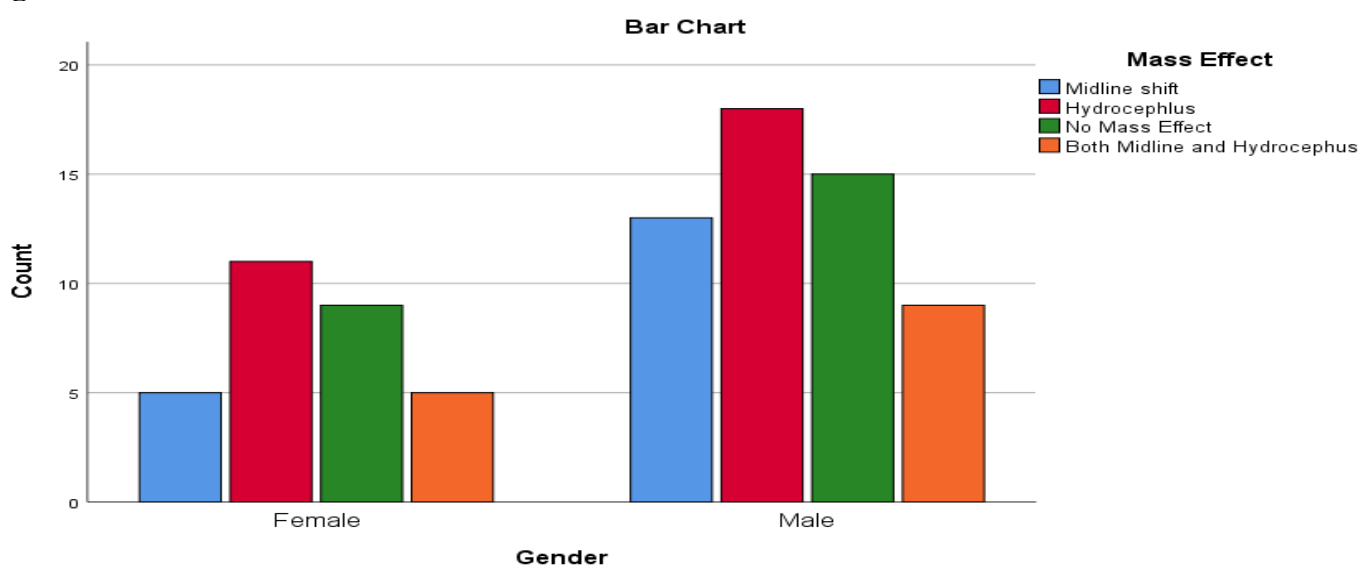

Affected Vessels

Gender-wise frequency of mass effect

Table: 5.6: $\mathrm{n}=\mathbf{8 5}$

Affected Vessels

\begin{tabular}{ccc|c|ccc} 
& & MCA & Anterior Cerebral Artery & Posterior Cerebral Artery & Total \\
\hline \multirow{2}{*}{ Gender } & Female & 16 & 6 & 8 & 30 \\
\cline { 2 - 7 } & Male & 33 & 7 & 15 & 55 \\
\hline \multicolumn{2}{c}{ Total } & 49 & 13 & 23 & 85 \\
\hline
\end{tabular}

Gender-wise frequency of affected vessels 
Fig: 5.6

\section{Gender-wise frequency of affected vessels}

Bar Chart

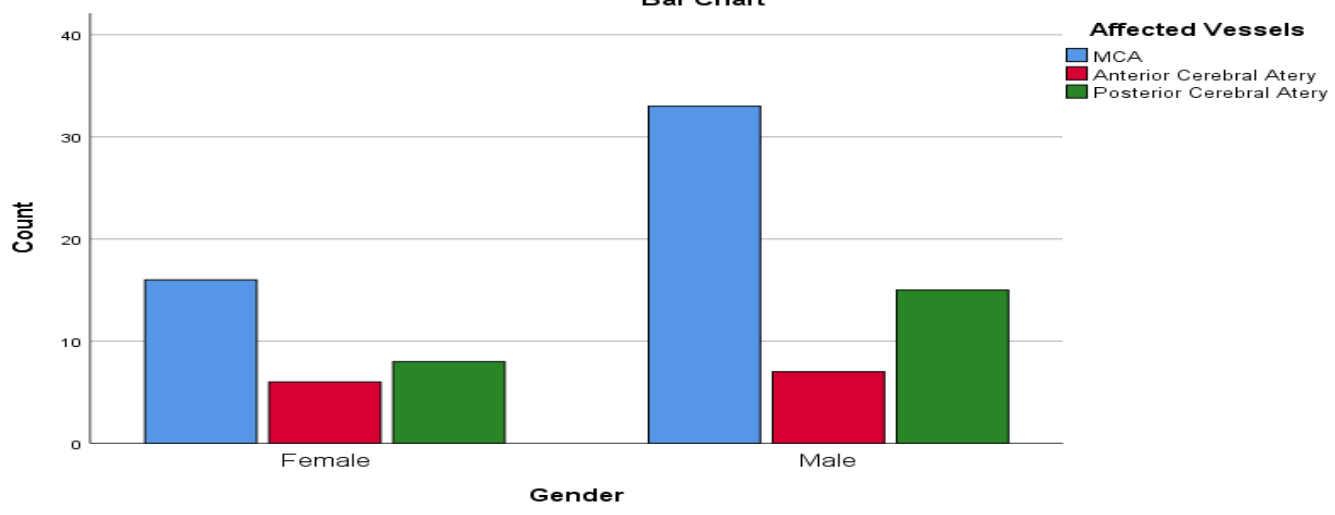

